\title{
Knowledge-Driven Economy As A Panacea For Economic Recession
}

\author{
Ukeh Micheal Eke \\ PhD Student, Department of Management, \\ Abia State University, Uturu, Nigeria. \\ Wilson Ani \\ Department of Finance, \\ Michael Okpara University of Agriculture, Umudike, Abia State.
}

\begin{abstract}
Recession and its attendant consequences are not new phenomena in the history of the world economy. In the advanced economies "knowledge" is fast becoming a strategic asset for combating recession and spurring economic development. Technological advances and globalization are gathering pace. For countries tapping in to the ideas, innovations and technologies that abound in a knowledge driven economy, there is a definite abundance of wealth and opportunities for all their people. The study identified the key issues of knowledge based economy; strategies that make a knowledge driven economy the panacea for economic recession, challenges and prospects. The study recommended among others the enthronement of an economic and institutional regime that would help articulate the strategies for easy transition to a knowledge economy, the development of an educated and skilled population with dynamic information infrastructure and effective innovation system and the development of the political and institutional will to effectively implement innovation, education and ICT strategies for better result.
\end{abstract}

Keyword: Recession, knowledge-driven, innovation, knowledge management.

\section{INTRODUCTION}

Recession and its attendant consequences are not new phenomena in the history of the world economy. Exciting trends are sweeping across the world. In the advanced economies "knowledge" is fast becoming a strategic asset for economic development. Technological advances and globalization is gathering pace. Advances in information and communication technology are occurring on a tremendous scale. For countries tapping into the new ideas, innovations and technologies that proliferate in a knowledge-driven economy, there is a definite abundance of wealth and opportunities for its entire people.

Altenburg and Melia (2014), observe that changes in the global pattern of economic growth reveal that economies are now growing with regards to how they exploit knowledge and technology and not just their possession of natural resources. Sub-Sahara African economies seem not to follow this growth pattern as most are still natural resource driven and not engaged in productive investments and creation. This study addresses issues relating to knowledge-driven economy and how it could be a panacea to emerging economies in recession. The competiveness of economies is increasingly dependent on their ability to create, use and diffuse knowledge. A knowledge-driven economy is one in which the generation and use of knowledge play the major part in the creation of wealth. It is not simply about pushing back the frontiers of knowledge; it is also about the effective use and exploitation of different types of knowledge in all manner of economic activity (Adekemi, 2015). To address this concept thoroughly, the study is set to achieve the following objectives: 
- To identify the key issues of knowledge-based economy.

- To determine the strength of knowledge-driven economy as a panacea to economic recession.

- To identify the challenges and prospects of knowledge-driven economy in an economy in recession.

\section{Economic Recession}

\section{CONCEPTUAL REVIEW}

Lasisi and Shodiya (2017) opine that traditionally, Economists define recession as two successive quarters of decline in the growth of Gross Domestic Product (GDP).Going by the report of Nigeria Bureau of statistics (NBS), Nigeria delved into recession in 2016. The double quarters of negative growth, high levels of inflation, worsening purchasing power of naira and the increasing levels of unemployment were strong indicators that all was not well. They further observe that a recession has many attributes that can occur simultaneously and includes decline in component measures of economic activity such as consumption, investments, government spending and net export activity. The summary of measures reflect underlying drivers such as employment levels and skills, household saving rates, corporate investment decisions, interest demographics and government policies.

Otuonye, Nwaimo and Udunma (2017) observe that the National Bureau of Economic Research (NBER) defined a recession as:

"A significant decline in economic activity spread across the macro economy, lasting more than a few months, normally visible in a real gross domestic product (RGDP), real income, employment, industrial production, and wholesale-retail sales."

They stated that an economic recession can also be defined as a negative real GDP growth rate for two consecutive quarters. In view of the above definition, Nigeria witnessed economic recession since her GDP growth rate in the first and second quarters of 2016 were $-0.36 \%$ and $-1.5 \%$ respectively.

Afe (2017), asserts that the International Monetary Fund (IMF), as well as the Central Bank of Nigeria, agreed that the Nigerian economy entered a recession and asserted that the economy might not regain stability too soon going by the growth rate of $1.5 \%$. Recession generally occur when there is a widespread drop in spending. This may be triggered by various events, such as a financial crisis, an external trade shock, an adverse supply shock or the bursting of an economic bubble. Usually, recession may be triggered by financial crisis and or credit crunch, as well as demand and supply side shocks, (Kamar, 2012).

\section{Knowledge-Driven Economy}

A knowledge-driven economy is one in which the generation and the use of knowledge play the major part in the creation of wealth. It is not simply about pushing back the frontiers of knowledge; it is also about the effective use and exploitation of different types of knowledge in all manner of economic activity. European Union (EU) 2004, observes that economies have been increasingly knowledge-based for a long time. Currently, however, four influences can be identified as increasing the speed of change:

1. Extraordinary progress of information \& communication Technologies (ICT).

2. Increased speed of scientific and technological advance.

3. Increase global competition, facilitated in part by reduced communication cost.

4. Change in demand associated with rising incomes, and the changes in tastes and attitudes to leisure that come with greater prosperity. 
They further opined that today, we have moved away from the resource-based economy to the knowledge-based. What is important to emphasize is that knowledge currently contributes significantly to the dynamics of the European economy. The World Bank (1998) noted also that the increasing importance of knowledge is changing the way firms compete and the sources of comparative advantage between countries. It is a reality that for countries in the vanguard of the world economy, the balance between knowledge and resources has shifted so far towards the former that knowledge has become perhaps the most important factor determining the standard of living. Today's most technologically advanced economies are truly knowledgebased.

The World Bank (1998) further stressed that the main changes associated with knowledge as an economic driver in today's economies are:

1. Knowledge is increasingly considered to be a commodity. It is packaged, bought and sold in ways and to levels never seen before.

2. Advances in ICTs have reduced the cost of many aspects of knowledge activity, for example knowledge gathering and knowledge transfer.

3. The degree of connectivity between knowledge agents has increased dramatically.

World Bank (2004) infers that a Knowledge-Based Economy (KBE) is "one where organizations and people acquire, create, disseminate and use knowledge more effectively for greater economic and social development".

OECD (1996) notes that the term "Knowledge-based Economy" results from a fuller recognition of the role of knowledge and technology in economic growth. Knowledge, as embodied in human beings (as "human capital") and in technology has always been central to economic development. But only over the last few years has its relative importance been recognized, just as that importance is growing. The OECD economies are more strongly dependent on the production, distribution and use of knowledge than ever before. Output and employment are expanding fast in high-technology industries such as computers, electronics and aerospace.

The OECD (1996) defines knowledge based economies as economies which are directly based on production, distribution and use of knowledge and information. Chukwuemeka (2016), observe that the knowledge economy has taken roots in quite a number of countries and some of the countries like India and Singapore have started to reap the benefits. Debbie (2000) noted that Nigeria needs a change of direction. The forces of change outside Nigeria are driving the need for change within it. Therefore, to maintain itself on a par with the rest of the world, and to be able to compete successfully in the fast moving world economy, Nigeria has to radically reform itself. Chukwuemeka (2016) further observed that the Minister of Science and technology, Dr. Ogbonnaya Onu, was credited as saying that "It has become clear that nation that desires to develop, modernize her economy and remain competitive, must embrace knowledge, especially, scientific and technological knowledge and that the need to move from resource-based economy to knowledge based economy is necessary now more than ever before, considering the recent near collapse in Crude oil prices that exposed the vulnerability of the Nigerian economy".

\section{Issues/Pillars of the Knowledge-Based Economy}

There is a wide spectrum of factors which are relevant to the knowledge economy. The World Bank Institute (2004) identifies four key aspects of an economy, which are regarded as the Pillars of the knowledge economy. It is expected that these pillars would help countries articulate strategies for their transition to a knowledge economy. 


\section{Economic and Institution Regime (EIR)}

This comprises incentives that stimulate and promote enterprise development via knowledge creation, dissemination and use. The process of knowledge creation and diffusion in a knowledge-based economy heavily depends on appropriate government policies that are usually the outcome of economic incentives and institutional regimes (Debnath, 2011). By implication, addressing tariff and untariff barriers, improving regulatory quality and improving the rule of law will influence how quickly individuals can identify and exploit market opportunities to create wealth, jobs and economic growth. In addition, improving the policy and business environments to create conditions favourable to trade is one of the most important ways for countries to obtain knowledge from abroad (World Bank, 1998).

\section{An Educated and Skilled Population}

Radwin and Pellegrini (2010) observe that a highly skilled and flexible human capital is essential to compete effectively in today's world and is a key building block of a knowledgebased economy. Access to basic education, number of years of schooling and exposure to tertiary level of education determine the proportion of the economy that is literate.

\section{A Dynamic Information Infrastructure}

Access to ICT infrastructure facilitates the effective communication, dissemination, and processing of information. The infrastructure strength and coverage of the telecommunications sectors is revealed in the number of people with ability to use computers, with access to internet and the mobile telephone subscriber base. Number of internet user serves as an indication of how well a population has advanced to the level of adapting using advanced communication channels to serve its priorities.

\section{An Effective Innovation System}

This allows for close relations among knowledge institutions (research centers, universities) and firms with which they can tap into the growing stock of global knowledge, adapt it to local needs, and create new technological solutions. Effective use of knowledge in any country requires appropriate policies, institutions, investments and coordination across these four pillars. Adekemi (2015), posits that in a full- fledged knowledge- based economy, one can expect to find the following:

- Full recognition of the role of knowledge and technology in an economic growth;

- Increase in the contribution of knowledge-intensive sectors and the service sector to GDP;

- Investments are directed towards high-technology goods and services (particularly information and communications technologies.

- R \& D and human capital development (education and training),

- Highly-skilled labour is highest demand; and

- Strong University- Industry collaborations

\section{STRATEGIES FOR DEVELOPING A KNOWLEDGE-DRIVEN NIGERIAN ECONOMY}

The requirements for building a knowledge economy are greater than resource abundance. A knowledge economy strongly depends on new technology investments, high-technology industries and highly skilled labour (Blankley and Booyens, 2010). However, Debbie (2000) observe that there is no disguising the phenomenal scale of work, commitment and seriousness that needs to be inputted before Nigeria can lay claim to being knowledge driven. It demands complete stage of culture and attitude. Not only that, there needs to be a new name of collaboration and joint working between different agencies and different sectors of the 
economy to make it a reality. The first step then is for the government to put in place a cohesive and cohered long-term strategy to make the idea a reality.

Adekemi (2015) identified the four pillars of the knowledge economy in Nigeria that still require significant interventions, investments and reforms. He opined that what is simply required is to strengthen each of the four pillars.

Economic and Institutional Regime: NBS 2010 survey report pointed whether Micro, Small and Medium Enterprises in Nigeria contributes significantly to GDP (46\%), this sector should be well developed via the creation of conducive environment. He postulates that borrowing a leaf from Singapore, it is crucial to ensure continuity in economic and industrial policies and make the business environment secure enough to increase private sector participation and attract foreign direct investment setting up a commission to monitor the country's transition into a knowledge of economy is also an important strategy.

Innovation: To build capabilities for technological adoption, Nigeria can tow the path of emerging economies such an India, to exploit reverse engineering techniques. To do this however, there is great need to improve the engineering design capacity and the technology absorption capacity of the country. In addition, fostering a culture of respect for intellectual Property Rights must not be underplayed. The new STI policy offers opportunities for commercialization of research outputs. Hence, adequate attention should be given to its implementation.

Education: The strength (in numbers) and entrepreneurial spirit of the youth population in Nigeria should be optimized. This can be done through adequate investments in educational training. In particular, incentives to encourage undergraduate study in science and engineering fields should be introduced. The needs of the education sector may be addressed by establishing educational centers for the development of knowledge intensive skills.

ICT: The noticeable productivity in the ICT sector has been enabled by high level competition among private firms, because of readiness to creativity and innovation. Given its sustained growth rate of the ICT sector, Nigeria can leverage on her ICT sector, especially mobile telephoning services to significantly improve her KE ranking in the next few years. In addition, adequate investments should be made to extend ICT services to rural areas and improve the national level of computer literacy.

In addition to the four pillars identified by the World Bank, Nigeria has other sectors in which increased creativity and innovation is being observed. One of such is the entertainment industry (Nollywood) which has risen to prominence within and beyond Nigeria and is now ranked alongside American's Hollywood and India's Bolly wood (Oyewunmi, 2011). The appropriate exploitation of the role of digital technology in the creation and dissemination of entertainment works in Nigeria has the potential of increasing the overall knowledge performance of the economy.

\section{CHALLENGES OF THE KNOWLEDGE-DRIVEN ECONOMY}

In the knowledge driven economy, establishing bridges between knowledge and the market place and putting in place the right environment for innovation are the key to building competitiveness. The knowledge economy also represents new opportunities and requires some design actions to support and take advantage of this economy (Liikanen, 2003). 
It is the firm that organizes the creation of value. With the shortening of product cycles, firms face the need for more capital-intensive investment and must put more emphasis on the ability to react quickly. For firms, innovation is a crucial means of create competitive advantage and superior customer value. Except for certain types of technology based firms, the focus is not on the technological aspects of new product development, but on innovative ways to improve their position in the market.

The challenges of the new knowledge-driven economy can be classified into the following groups (Antonio and Jose, 2007).

- New characteristics of the market. The market is constantly changing, it is becoming more global and new competitors are emerging. In addition technology complexity is increasing, product life-cycles are shortening and knowledge is consolidating as a crucial input. All of these are characteristics of the market require the development of additional competitiveness from firms.

- New type of innovation. Innovation takes many forms. There is technological innovation, but also innovation through new business models and new ways of organizing work, innovation in design and in marketing. Innovation can also consist of finding new uses and new markets for existing products and services. It emerges where the market offers incentives to introduce new products and production methods, and where people are willing to take risk and experiment with new ideas.

- New needs of Stakeholders. Customers, owner and stock markets increasingly equate an organization's work with its ability to get winning products to market on time, every time.

- New approach to Innovation Management. Innovation management encompasses all the key areas that need to be mastered to develop successful products and services, efficiently and continuously. Innovation management is a prime driver for top-line growth and bottom-line efficiency in every industry where innovation is not just limited to product innovation but also comprises business and process innovation. The capacity of a firm to implement innovation management revolves around its success in dealing with these two main challenges, top-line growth and bottom-line efficiency.

\begin{tabular}{|c|c|}
\hline TOP-LINE GROWTH & BOTTOM-LINE EFFICIENCY \\
\hline $\begin{array}{l}\text { How do we create new growth by exploiting our } \\
\text { business in new ways? }\end{array}$ & - How do we become more effective and efficient? \\
\hline $\begin{array}{l}\text { - How do we develop an integrate product and } \\
\text { technology strategy plan in a powerful way? }\end{array}$ & $\begin{array}{l}\text { What is the best direction for our R\&D, } \\
\text { technology and products/services creation? }\end{array}$ \\
\hline $\begin{array}{l}\text { - How do we ensure that creativity is not being } \\
\text { killed by bureaucracy? }\end{array}$ & $\begin{array}{l}\text { - How do we ensure that correct importation is } \\
\text { being used to select. }\end{array}$ \\
\hline $\begin{array}{l}\text { - How do we ensure that more of our ideas lead to } \\
\text { successful products? }\end{array}$ & $\begin{array}{l}\text { - How do we manage the risks associated with the } \\
\text { introducing new fast moving technologies? }\end{array}$ \\
\hline
\end{tabular}

Source: Antonio, H \& Jose, A (2007) Innovation management techniques and tools: a review from theory and practice. Citeseerx.ist.psu.edu

- New technology innovation assessment skills. The rapid development of new technologies prompts firms to assess and implement the most appropriate technology according to their need to keep their competitiveness such a challenge can be too much ever the most successful business (Christensen, 1997) due to:

- Failure to distinguish between technologies that are sustaining and those that are disruptive.

- Technological progress that often outstrips market demand. This means companies tend to over shout the market giving customers more than they want or are willing to pay for. 
- Pressures from both customers and shareholders that influence the innovation in which firms engage.

- Need for new innovation management tools. The development of knowledge-based innovation management requires the capacity to implement technical and relational tools. Technical tools refer to the acquisition and utilization of new information and communication technologies-they do not create competitive advantage because they are readily available to others. The creation of competitive advantage rests in relational tools-the way of firms(Antonio and Jose, 2007).

\section{CONCLUSION}

Knowledge holds the key to modernizing the Nigerian economy. However, to achieve this, the government needs to put in place a proper economic framework to help drive the economy. The transition to a knowledge-driven economy requires sustained commitment to investing in human capital, ICT, innovation and good governance. It involves a change of culture and attitude, and in particular in fostering a new spirit of transparency and openness in all aspects of Nigeria life. It also involves collaboration between the government, the private sector, the education sector and the Nigerian populace as a whole. It is only then can Nigerian aim to successfully compete in the fast growing global economy.

\section{RECOMMENDATIONS}

Government is a critical factor in fostering the knowledge-driven economy that will make the nation transit smoothly from the resource-based economy to knowledge based in other to compete favorably on the global economy. We recommend that the pillars that would help articulate the strategies for easy transition to a knowledge economy be put in place such as the economic and institutional regime. An educated and skilled population be developed with a dynamic information infrastructure and effective innovation system, since it has been established that appropriate strategies are inevitable.

It is our strong opinion and recommendation that the government develops the political and institutional will to effectively implement the strategies such as innovation, education and ICT for a better result.

\section{References}

Adekemi, J. O. (2015). Towards a Knowledge-Based Economy: Challenges and Opportunities for Nigeria. International Conference on African Development Issues (CU-ICADI).Social Economic Models for Development Track.

Altenburg, T. and Melia, E. (2014). "National Resource Endowment and Industrial Development in Sub-Saharan Africa" presented at the 12th Globelies Conference in Addis Ababa, Ethiopia, 29 - 31 October.

Antonio Hidalgo and Jose Albors (2007). Innovation management techniques and tools: a review from theory and practice. Citeseerx.ist.psu.edu

Blankley, W. O. and Booyens, I. (2010).Building a Knowledge Economy in South African, South Afr. J. Sci. Vol. 106.

Brown, H. A. and Jacques, B. (2006).Empirical Studies of Innovation in the Knowledge-Driven Economy.Econ.Innov.New Techn. 15(4/5): 289-299.

Chika Jones (2016). Economic Recession in Nigeria: Causes and Solution. www.educainfo.com.

Chukwuemeka, F. A. (Jnr) (2016). Developing knowledge economy in Nigeria.Punch Newspaper December 18, punching.com/developing-knowledge- economy.

Debbie Ariyo (2000). Developing a Knowledge-Driven Nigerian Economy: An Economic Framework for the 21st Century.Africa Economic Analysis.www.afbis.com/analysis/knowledge.htm.

Deborath, S. C. (2011). Key Determinants of Economic Incentives and Institutional Regimes to Promotes Knowledge-Based Economy in East Asia. Ritsumikan International Affairs, 10, 183-218. 
European Union (2004).

Kamar, B. (2012). Financial Crisis.International Monetary Fund Institute for Capacity Development.

Lasisi, J. O> and Shodiya, O. A. (2017). Business development and economic recession in Nigeria: Lessons and the way forward. The Business and Management Review, volumes 8 Number 4.

Organisation for Economic Cooperation and Development (OECD), The knowledge-Based Economy Paris 1996. OCDE/GD (96) 102.

Otuonye, A. I., Nwaimo, C. E.; \&Udunwa, I. A. (2017). Remedy to Economic Recession in Nigeria: an ICT-Driven model for a sustainable Economic Growth. International Journal of Science and Research Methodology Vol. 6 Issue 4.

Oyewunmi, A. (2011). Towards Sustainable Development of Nigeria's Entertainment Industry in the Digital Age: Role of Copyright Law and Administration. NIALS Journal of Intellectual Property (NJIP) Maiden Edition.

Radwan, I. and Pellegrini, G. G. (2010). Knowledge, Productivity and Innovation in Nigeria: Creating a New Economy. The International Bank for Reconstruction and Development/the World Bank: Washington, D. C.

Russell, Lawson (2012). The Importance of Innovation in a Knowledge-Driven Economy.http://Hig.org/theimportance-of-innovation-in-a-knowledge-drive-economy.

World Bank (1998).Knowledge for Development. World Bank Development Report 1998/99. World Bank: Washington, D. C.

World Bank (1998).Knowledge for Development. World Development Report, New York, Oxford University Press. 